\title{
HUBUNGAN PENGETAHUAN DENGAN SIKAP REMAJA PUTRI TENTANG PEMERIKSAAN PAYUDARA SENDIRI DI SMA NEGERI 7 TANJUNG BALAI TAHUN 2019
}

\author{
Herlia Sumardha Nasution', Nila Hayati ${ }^{2}, \mathbf{A d e}^{3}$ \\ STIKes Rumah Sakit Haji Medan, Indonesia
}

Article Info

\section{Keywords:}

Knowledge

Youth Attitude

Breast

\begin{abstract}
Breast cancer is the most feared breast disorder for women, because this disease can not be cured if found at an advanced stage of women is needed to know about breast cancer the purpose of this study is to know there is a Relationship between Knowledge and Attitudes of Young Women About Breast Examination at 7 Tanjung High School Balai Balai 2019 ". This study uses cross-national research design. The population in this study were all students of Tanjung Balai 7th Senior High School in class XI with a sample of 60 students, with the sampling technique of total sampling the number of smapels in this study was 60 people. Data analysis techniques were carried out using univariant and bivariate statistical analysis. The statistical test in this study, used the chi square formula (kai squared) to estimate or evaluate the frequency under investigation has a significant or no relationship, with a $95 \%$ confidence level. Based on the results of the study There is a positive and significant relationship between the knowledge and attitudes of young women about breast selfexamination in Tanjung Balai 7 High School in 2019, where the $p$ value $=0.032(\mathrm{p}<0.05)$. For this study can add insight and knowledge for young women to pay more attention to the Dengan gers of breast cancer and prevention by examining their own breasts and can apply to everyday life.
\end{abstract}

This is an open access article under the CC BY-SAlicense.

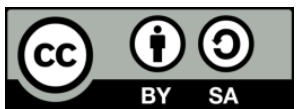

\section{Corresponding Author:}

Herlia Sumardha Nasution,

Program Studi D-III Kebidanan,

STIKes Rumah Sakit Haji Medan,

Jl. Rumah Sakit H., Medan Estate, Kec. Percut Sei Tuan, Kabupaten Deli Serdang, Medan-Sumatera Utara.

Email: herliasumardha5787@gmail.com

\section{INTRODUCTION}

Kanker payudara merupakan kelainan payudara yang paling ditakuti perempuan, karena penyakit ini tidak dapat disembuhkan jika ditemukan pada stadium lanjut. Padahal, jika dideteksi sejak dini, penyakit ini sebetulnyabisadiobati sampai sembuh (Luwia, 2013).

Berdasarkan data Global Of Cancer (GLOBOCAN), International Agency for Research on Cancer (IARC), diketahui bahwa kanker payudara adalah kanker paling umum kedua di dunia dan merupakan kanker yang paling sering diantara perempuan dengan perkiraan 1,67 juta kasus kanker baru yang di diagnosis pada 
tahun 2012 (25\% dari semua kanker). Kasus kanker payudara lebih banyak terjadi di daerah kurang berkembang (883.000 kasus) dibandingkan dengan daerah yang lebih maju (794.000 kasus) (Kemenkes RI, 2016).

Tingkat Incidence Rate (IR) bervariasi hampir empat kali lipat di seluruh wilayah dunia, mulai dari 27 kasus per 100.000 di Afrika Tengah dan Asia Timur sampai 92 kasus per 100.000 di Amerika Utara. Kanker payudara menempati urutan sebagai penyebab kelima kematian akibat kanker secara keseluruhan sekitar 522.000 kematian dan sementara itu merupakan penyebab kematian yang paling sering terjadi pada perempuan di daerah yang kurang berkembang sekitar 324.000 kematian (14,3\% dari total), kanker payudara juga menjadi penyebab kedua kematian akibat kanker di daerah yang lebih maju sekitar 198.000 kematian $(15,4 \%)$ setelah kanker paru. Kisaran angka kematian antar wilayah dunia kurang dari itu karena kelangsungan hidup yang lebih menguntungkan dari kanker payudara pada daerah berkembang, mulai dari 6 kematian per 100.000 penduduk di Asia Timur sampai 20 kematian per 100.000 penduduk di Afrika Barat sedangkan angka kematian di Indonesia untuk kanker payudara adalah 16,6 kematian per 100.000 penduduk (Kemenkes RI, 2016).

Hasil penelitian Itayanni (2015) tetang kanker payudara di kelurahan Palopat Maria lingkungan II kecamatan Padang Sidempuan diketahui dari 30 responden mayoritas berpengetahuan kurang sebanyak 15 responden $(50 \%)$, berdasarkan umur mayoritas berpengetahuan kurang sebanyak 6 responden(20\%) berdasarkan pendidikan mayoritas berpengetahuan kurang sebanyak 13 responden (43,3\%) berdasarkan sumber informasi mayoritas berpengetahuan kurang sebanyak 13 (43,3\%), untuk itu diperlukan penyuluhan kesehatan tentang pemeriksaan dini pada daerah tersebut sehingga dapat menurunkan angka kesakitan dan kematian.

Penelitian yang telah dilakukan oleh Septiani (2013) dengan melakukan pemeriksaan payudara sendiri (SADARI) akan menurunkan tingkat kematian akibat kanker payudara sampai 20\%, namun wanita yang melakukan SADARI masih rendah (25\%-30\%). Masih kurangnya kesadaran wanita-wanita Indonesia khususnya remaja dalam melakukan deteksi dini terhadap kanker payudara menyebabkan angka kejadian kanker payudara cukup besar (Permatasari, 2013)

Salah satu strategi untuk meningkatkan pengetahuan Dengan Sikap siswa terhadap kesehatan adalah melalui pendidikan kesehatan. Pendidikan kesehatan yang diberikan secara dini, akan memudahkan remaja mencapai sikap dan tingkah laku yang diinginkan yaitu sikap dan tingkah laku yang bertanggung jawab. Oleh karena itu, sebagai upaya preventif sekaligus promotif yang dapat memberikan gambaran gaya hidup sehat kepada remaja saat ini adalah dengan cara memberikan pendidikan kesehatan kepada remaja Indonesia (Notoatmodjo, 2012) Pendidikan kesehatan tentang pemeriksaan payudara sendiri sangat dibutuhkan untuk perilaku SADARI remaja, agar remaja tidak mengalami gangguan kesehatan pada payudaranya dan juga diperlukanperan petugas kesehatan untuk melakukan health education agar remaja mengerti SADARI (Syaiful,2016).

Remaja putri mempunyai resiko yang besar untuk terkena kanker payudara. Berdasarkan informasi yang didapatkan dari Badan Pusat Statistik diketahui bahwa jumlah remaja putri yang bersekolah di tingkat SMA Negeri 7 Tanjung Balai semakin bertambah dan diketahui bahwa jumlah siswi di SMA Negeri 7 Tanjung Balai semakin bertambah dari tahun ke tahun. Berdasarkan hasil survei awal yang telah dilakukan diketahui bahwa pengetahuan siswi SMA Negeri 7 Tanjung Balai masih kurang Dengan Sikap yang tidak peduli tentang SADARI. Hal ini diketahui dari 10 siswi yang di wawancarai terdapat 6 siswi yang mengatakan terdapat benjolan pada payudara mereka namun tidak ada satupun dari mereka yang mengetahui tentang SADARI serta sikap yang tidak peduli tentang SADARI dan 4 siswi yang mengatakan terdapat tidak terdapat benjolan pada payudara mereka dan tidak mengetahu SADARI serta sikap yang tidak pedulu tentang SADARI. Berdasarkan informasi yang didapat dari kepala sekolah dan guru - guru diketahui bahwa belum pernah dilakukan penyuluhan tentang SADARI di sekolah ini. Berdasarkan hal tersebut maka dipilih SMA Negeri 7 Tanjung Balai sebagai lokasi penelitian.

Menemukan adanya fakta bahwa salah satu jenis kanker yang paling sering terjadi pada wanita adalah kanker payudara dan sebagian besar terdeteksi pada stadium lanjut, hal ini menimbulkan ketertarikan tersendiri bagi peneliti untuk meneliti bagaimana pengetahuan Dengan Sikap tentang SADARI sebagai salah satu cara untuk mendeteksi dini kanker payudara.

Berdasarkan latar belakang masalah diatas maka penulis tertarik untuk melakukan penelitian di SMA Negeri 7 Tanjung Balai dengan judul "Hubungan Pengetahuan Dengan SikapRemaja Putri Tentang Pemeriksaan Payudara Sendiri Di SMA Negeri 7 Tanjung Balai Tahun 2019. Berdasarkan uraian diatas maka perumusan masalah adalah "Hubungan Pengetahuan Dengan Sikap Remaja Putri Tentang Pemeriksaan Payudara Sendiri Di SMA Negeri 7 Tanjung Balai Tahun 2019?” 


\section{RESEARCH METHOD}

Penelitian ini menggunakan desain penelitian crossecsional. Populasi dalam penelitian ini adalah seluruh siswa - siswi SMA Negeri 7 Tanjung Balai kelas XI dengan jumlah sample 60 siswa, dengan teknik pengambilan sample total sampling jumlah smapel dalam penelitian ini adalah 60 orang. Teknik analisa data dilakukan dengan menggunakan analisis statistik univariant Dengan bivarian. Uji statistik dalam penelitian ini, digunakan rumus chi square (kai kuadrat) untuk mengestimasi atau mengevaluasi frekuensi yang diselidiki memiliki hubungan yang signifikan atau tidak, dengan derajat kepercayaan $95 \%$.

\section{RESULTS AND ANALYSIS}

\subsection{Hasil}

Penelitian ini di SMA Negeri 7 Tanjung Balai dengan sampel sebanyak 60 responden yang diambil dari seluruh siswi kelas XI SMA Negeri 7 Tanjung Balai. Pengumpulan data dalam penelitian ini dilakukan dengan menggunakan kuesioner pengetahuan yang dibagikan kepada seluruh sampel dengan jumlah pertanyaan sebanyak 30 pertanyaan dan kuesioner sikap sebanyak 15 pertanyaan. Penelitian ini menggunakan desain korelasi untuk mengetahui hubungan pengetahuan Dengan Sikapremaja putri tentang pemeriksaan payudara sendiri di SMA Negeri 7 Tanjung Balai Tahun 2019

\section{Data Frekuensi Responden Berdasarkan Kelas} berikut ini :

Data Frekuensi Responden berdasarkan kelas dari hasil kuesioner didapatkan hasil dalam tabel

Tabel 1. Distribusi Frekuensi Berdasarkan Kelas di SMA Negeri 7 Tanjung Balai Tahun 2019

\begin{tabular}{cccc}
\hline No & Kelas & Frekuensi & Persentase \\
\hline 1 & XI - A & 30 & 50 \\
2 & XI - B & 30 & 50 \\
\hline & Jumlah & $\mathbf{6 0}$ & $\mathbf{1 0 0}$ \\
\hline
\end{tabular}

Berdasarkan tabel 1 diatas, diketahui bahwa dari 60 responden yang diteliti, 30 responden $(50 \%)$ diambil pada kelas XI-A dan 30 responden (50\%) diambil pada kelas XI-B.

Tabel 2. Distribusi Frekuensi Berdasarkan Kelas di SMA Negeri 7 Tanjung Balai Tahun 2019

\begin{tabular}{cccc}
\hline No & Umur & Frekuensi & Persentase \\
\hline 1 & 16 & 9 & 15,0 \\
2 & 17 & 41 & 68,3 \\
3 & 18 & 10 & 16,7 \\
\hline & Jumlah & $\mathbf{6 0}$ & $\mathbf{1 0 0}$ \\
\hline
\end{tabular}

Berdasarkan tabel 2 diatas diperoleh data sebagian besar responden berumur 17 tahun sebanyak 41 responden $(68,3 \%)$.

Tabel 3. Distribusi Frekuensi Responden Berdasarkan Pengetahuan Remaja Putri Tentang Pemeriksaan Payudara Sendiri Di SMA Negeri 7 Tanjung Balai Tahun 2019

\begin{tabular}{cccc}
\hline No & Pengetahuan & Frekuensi & Persentase (\%) \\
\hline 1 & Baik & 13 & 21,7 \\
\hline 2 & Cukup & 42 & 70,0 \\
\hline 3 & Kurang & 5 & 8,3 \\
\hline & Total & $\mathbf{6 0}$ & $\mathbf{1 0 0}$ \\
\hline
\end{tabular}

Berdasarkan tabel 3 diatas diketahui bahwa sebagian besar responden memiliki pengetahuan yang kurang tentang Pemeriksaan Payudara Sendiri (SADARI) yaitu sebanyak 22 responden (55\%) dari 40 responden yang diteliti.

Tabel 4. Distribusi Frekuensi Responden Berdasarkan Sikap Remaja Putri Tentang Pemeriksaan Payudara Sendiri Di SMA Negeri 7 Tanjung Balai Tahun 2019

\begin{tabular}{cccc}
\hline No & Sikap & Frekuensi & Persentase (\%) \\
\hline 1 & Positif & 28 & 46,7 \\
\hline 2 & Negatif & 32 & 53,3 \\
\hline & Total & $\mathbf{6 0}$ & $\mathbf{1 0 0}$ \\
\hline
\end{tabular}

Berdasarkan tabel 4 diatas diketahui bahwa sebagian besar remaja putri yang ada di SMA Negeri 7 Tanjung Balai Tahun 2019 memiliki sikap yang negatif sebanyak 25 responden $(62,5 \%)$. 
Tabel 5. Tabulasi Silang antara Hubungan Pengetahuan Dengan SikapRemaja Putri Tentang Pemeriksaan Payudara Sendiri Di SMA Negeri 7 Tanjung Balai Tahun 2019

\begin{tabular}{|c|c|c|c|c|c|c|c|c|c|}
\hline \multirow{3}{*}{ No } & \multirow{3}{*}{ Pengetahuan } & \multicolumn{4}{|c|}{ Sikap } & \multirow{2}{*}{\multicolumn{2}{|c|}{ Total }} & \multirow{3}{*}{$\chi^{2}$ hitung } & \multirow{3}{*}{$\mathbf{P}$} \\
\hline & & \multicolumn{2}{|c|}{ Positif } & \multicolumn{2}{|c|}{ Negatif } & & & & \\
\hline & & $\mathbf{f}$ & $\%$ & f & $\%$ & $\mathbf{f}$ & $\%$ & & \\
\hline 1 & Baik & 10 & 16,7 & 3 & 5,0 & 13 & 21,7 & \multirow{4}{*}{6,857} & \multirow{4}{*}{0,032} \\
\hline 2 & Cukup & 17 & 28,3 & 25 & 41,7 & 42 & 70,0 & & \\
\hline 3 & Kurang & 1 & 1,7 & 4 & 6,7 & 5 & 8,3 & & \\
\hline & Total & 28 & 46,7 & 32 & 53,3 & 60 & 100 & & \\
\hline
\end{tabular}

Hasil uji statistik chi square didapatkan nilai $\mathrm{p}$ value $=0,032(\mathrm{p}<0,05)$ sehingga Hipotesis Alternatif (Ha) diterima yang berarti ada hubungan yang positif dan signifikan antara pengetahuan Dengan Sikapremaja putri tentang pemeriksaan payudara sendiri di SMA Negeri 7 Tanjung Balai Tahun 2019.

\subsection{Pembahasan \\ Pengetahuan Remaja Putri Tentang Pemeriksaan Payudara Sendiri Di SMA Negeri 7 Tanjung Balai Tahun 2019}

Berdasarkan hasil penelitian dari 60 remaja putri diketahui bahwa sebagian besar remaja putri yang ada di SMA Negeri 7 Tanjung Balai memiliki pengetahuan yang cukup tentang Pemeriksaan Payudara Sendiri (SADARI) sebanyak 70\%. Hal ini menunjukkan bahwa responden belum sepenuhnya mengetahui apa itu SADARI dan bagaimana cara melakukan SADARI. Karakteristik responden yang masih digolongkan usia remaja dan sekolah, hal ini dipengaruhi oleh keberhasilan guru dari penyampaian pendidikan kesehatan di sekolah. Menurut Notoatmodjo (2015) bahwa anak yang sekolah merupakan kelompok yang sangat peka dan kritis untuk menerima perubahan atau pembaruan, karena kelompok anak sekolah sedang berada dalam taraf pertumbuhan dan perkembangan.

Menurut asumsi peneliti, bahwa hasil pengetahuan remaja putri yang masih tergolong kurang tentang pemeriksaan payudara sendiri (SADARI) disebabkan oleh kurangnya informasi yang diperoleh tentang SADARI, baik dari pendidikan kesehatan yang ada di sekolah maupun informasi yang diperoleh dari sumber yang lain sehingga mereka kurang mengerti tentang SADARI. Maka dari itu, Remaja putri di SMA Negeri 7 Tanjung Balai perlu sekali mengetahui dan memahami keadaan-keadaan pada payudara yang normal dan tidak normal agar ketika hasil pemeriksaan dengan SADARI telah didapat, remaja putri tersebut bisa membedakan apakah hasil yang didapat merupakan suatu keadaan yang normal atau tidak. Tindak lanjut dan penanganan dari petugas kesehatan perlu segera didapatkan oleh remaja putri jika saja keadaan tidak normal yang didapatkan ketika melakukan SADARI. Terlebih lagi saat ini kebanyakan siswi sudah lebih mudah mengakses informasi dengan menggunakan media internet dibandingkan dengan jenis media massa lainnya. Selain itu, media internet juga menyuguhkan informasi yang lebih kreatif dan memiliki edukasi yang baik.

\section{Sikap Remaja Putri Tentang Pemeriksaan Payudara Sendiri Di SMA Negeri 7 Tanjung Balai Tahun 2019}

Hasil penelitian pada variabel sikap remaja putri dalam melakukan SADARI di SMA Negeri 7 Tanjung Balai paling banyak memiliki sikap negatif sebanyak $32(53,3 \%)$ responden, sedangkan remaja putri yang memiliki sikap positif tentang SADARI sebanyak $28(46,7 \%)$ responden. Sehingga dapat disimpulkan sikap negatif dilihat dari hasil kuesioner yang menyatakan bahwa responden berpendapat pemeriksaan SADARI adalah sesuatu hal yang dianggap belum penting bagi remaja, SADARI sebaiknya hanya dilakukan oleh ibu rumah tangga.

Sikap negatif yang dimiliki responden dapat terjadi karena beberapa faktor dari ketakutan responden, pengalaman pribadi karena tidak ada yang memberitahu pada reponden bahwa pemeriksaan SADARI sangatlah penting selain itu didalam keluarga tidak ada yang melakukan pemeriksaan SADARI sehingga responden mengnganggap bahwa pemeriksaan SADARI tidaklah penting, media massa, media massa mampu memberikan pengaruh kepada perubahan sikap responden karena memberikan pengaruh jangka pendek. Dalam penyampaian informasi sebagai tugas pokoknya, media massa membawa pula pesanpesan yang berisi sugesti yang dapat mengarahkan opini seseorang.

Hasil penelitian ini sesuai dengan penelitian Sari Septiani (2012) dengan penelitian Sari Septiani (2012), dengan judul "faktor-faktor yang berhubungan dengan perilaku pemeriksaan (sadari) pada siswa SMAN 62 Jakarta" Hasil penelitian menyatakan Hampir seluruh responden memiliki pengetahuan yang baik tentang kanker payudara (98\%), namun hanya 58\% yang memiliki sikap positif terhadap kanker payudara. $81 \%$ responden mengakui bahwa mereka tidak terpapar oleh media tentang informasi terkait kanker payudara. 
Menurut peneliti hasil penelitian diatas menunjukkan bahwa responden memiliki sikap yang negatif, hal ini dapat dilihat dari sebagian besar responden yang belum memiliki kepedulian dalam melakukan SADARI. Hal ini dapat terjadi karena masih banyak responden yang merasa bahwa payudaranya baik-baik saja.

\section{Hubungan Pengetahuan Dengan SikapRemaja Putri Tentang Pemeriksaan Payudara Sendiri Di SMA Negeri 7 Tanjung Balai Tahun 2019}

Berdasarkan tabel diatas diketahui bahwa dari 60 responden, terdapat 42 responden yang memiliki pengetahuan yang cukup tentang SADARI yang mayoritas memiliki sikap yang negatif sebanyak 25 responden $(41,7 \%)$ dan responden yang memiliki sikap positif sebanyak 17 responden (28,3\%). Dari 13 responden yang memiliki pengetahuan baik tentang SADARI terdapat 10 responden $(16,7 \%)$ yang memiliki sikap positif dan 3 responden $(5,0 \%)$ yang memiliki sikap negatif. Sedangkan dari 5 responden $(8,3 \%)$ yang berpengetahuan kurang tentang SADARI terdapat 4 responden $(6,7 \%)$ memiliki sikap yang negatif dan 1 responden $(1,7 \%)$ memiliki sikap positif.

Hasil uji statistik chi square didapatkan nilai p value $=0,032(\mathrm{p}<0,05)$ sehingga Hipotesis Alternatif (Ha) diterima yang berarti ada hubungan yang positif dan signifikan antara pengetahuan Dengan Sikapremaja putri tentang pemeriksaan payudara sendiri di SMA Negeri 7 Tanjung Balai Tahun 2019.

Hasil penelitian ini sesuai dengan penelitian Nurmala Sari (2017) yang mendapatkan hasil bahwa ada hubungan tingkat pengetahuan remaja putri dengan sikap melakukan pemeriksaan payudara sendiri (SADARI) di SMAN 2 Ngaglik Sleman Yogyakarta nilai $p$-value sebesar $0,003<0,05$. Seseorang yang memiliki pengetahuan yang baik terhadap SADARI ini sangat bisa mempengaruhi perilaku Dengan Sikapuntuk melakukan SADARI. Responden yang memiliki pengetahuan yang baik terhadap bahayanya kanker payudara, akan membuat responden termotivasi juga untuk melakukan SADARI.

Tingkat pengetahuan responden didapatkan dalam kategori cukup. Hal ini menandakan bahwa responden telah memiliki pengetahuan yang baik terkait pemeriksaan SADARI. Pengetahuan yang baik tersebut disebabkan faktor media massa, seperti dalam teori Notoatmodjo (2007) menyatakan bahwa faktorfaktor yang mempengaruhi pengetahuan responden yaitu faktor pendidikan, media massa, sosial budaya, usia, lingkungan dan pengalaman.

Berdasarkan hasil penelitian di atas, maka peneliti berasumsi bahwa pengetahuan merupakan faktor yang akan memengaruhi sikap siswi dalam melakukan SADARI, dimana semakin baik pengetahuan responden maka semakin baik pula sikap remaja putri dalam melakukan SADARI. Hasil tersebut sesuai dengan pendapat Amali (2009) bahwa seseorang yang memiliki pengetahuan yang baik terhadap SADARI ini sangat bisa mempengaruhi perilaku Dengan Sikapuntuk melakukan SADARI, Dengan responden memiliki pengetahuan yang baik terhadap bahayanya kanker payudara, sehingga responden akan termotivasi juga untuk melakukan SADARI.

\section{CONCLUSION}

Berdasarkan hasil penelitian dan pembahasan, dapat disimpulkan sebagai berikut:

1. Pengetahuan tentang Pemeriksaan Payudara Sendiri (SADARI) pada remaja putri di SMA Negeri 7 Tanjung Balai Tahun 2019, sebagian besar tergolong masih cukup yaitu sebesar $70 \%$.

2. Sikap remaja putri tentang pemeriksaan payudara sendiri di SMA Negeri 7 Tanjung Balai Tahun 2019, mayoritas memiliki sikap positif yaitu sebesar 53,3\%.

3. Ada hubungan yang positif dan signifikan antara pengetahuan Dengan Sikapremaja putri tentang pemeriksaan payudara sendiri di SMA Negeri 7 Tanjung Balai Tahun 2019, dimana nilai p value $=0,032$ $(\mathrm{p}<0,05)$.

\section{REFERENCES}

Aryani., 2013., Kanker Payudara. Dalam: Deteksi Dini Kanker dan Simplisia Anti kanker. Penebar Swadaya,Jakarta.

Azwar, Abdi, 2013. Beberapa Sikap Yang Terdapat Pada Individu. (Online), (http://pkhbbrpSikapindividu/nmf/hdp.com,diakses 11Agustus 2019).

Hidayat., 2015,. Psikologi Perkembangan, edisi ke 5. PT Gelora Aksara Pratama, Jakarta.

Kemenkes RI., 2016. Menuju Masyarakat Sehat Dan Mandiri Dan Berkeadilan. diakses tanggal 22 september 2019. http://www.Kejadian infeksi pada persalinan. Depkes.co.id. 2011.

Otto., 2015. Studi Intervensi Pemberian Pelatihan SADARI Terhadap Perubahan Pengetahuan, Sikap dan Praktik SADARI Sebagai upaya Deteksi dini Kanker Payudara. Abstrak.

Permatasari., 2013., Dasar-Dasar Metodologi Penelitian Kedokteran dan Kesehatan. PT. Raja Grafindo Persada, Jakarta. 
Sarwono., 2015, Kanker Payudara Bisa Dideteksi Sendiri. (Online), (http://www.gizi.net/cgibin/berita/fullnews.cgi?newsid1010552074,29807, diakses 24oktober 2019).

Syaiful., 2016., Deteksi Dini Kanker Payudara dan Penanggulangannya. Dalam: Ramli, H.Muchilis, ed. Deteksi Dini Kanker, Cetakan ketiga, Fakultas Kedokteran Universitas Indonesia, Jakarta. 